\title{
EURRECA: importance of selecting useful biomarkers of status when deriving micronutrient requirements and dietary recommendations
}

\author{
A. Casgrain, L. J. Harvey, L. Hooper, R. Collings and S. J. Fairweather-Tait \\ University of East Anglia, Norwich NR4 7TJ, UK
}

The EURRECA Network of Excellence aims to provide information, tools and guidance that can be used for deriving micronutrient requirements. The network is focused on high-priority micronutrients for which risk of inadequacy is relatively high, recommendations are inconsistent and where there are new data on intake-status-health relationships.

Understanding the relationship between dietary intake and micronutrient status is essential for deriving dietary requirements. The main goal of the EURRECA 'Biomarkers of Status' research activity was to assess the reliability of biomarkers for selected priority micronutrients. This was approached in a two-stage process, incorporating eminence and evidence-based contributions. The first stage involved holding a workshop with invited international micronutrient experts and EURRECA partners to discuss state-of-the-art biomarkers of key micronutrients $^{(1)}$ and a working party was established to review current knowledge. An eminence-based table of biomarkers of status (covering both exposure and body levels) was drawn up by the experts, rating the quality of current biomarkers and their applicability to research or fieldwork.

In the second stage EURRECA partners undertook systematic reviews of biomarkers of status for $\mathrm{Zn}, \mathrm{Cu}$, Se, iodine, riboflavin, vitamins $\mathrm{B}_{12}$ and $\mathrm{D}$ and $n-3$ fatty acids ${ }^{(2)}$. This series of systematic reviews offers a thorough and unbiased analysis of biomarkers used in human intervention studies, assessing how they changed in response to supplementation and/or depletion, and addressing differences in measurement techniques. The results of the evidence-based reviews have been combined with the eminence-based table into a set of best practice guidelines for biomarkers of status. This web-based document will be disseminated to policy-makers, the medical profession and the wider research community for maximum impact. Designed as a quality assessment tool for setting nutrient recommendations, it is also an essential tool for the next phase of EURRECA research activities identifying those biomarkers that can be used in a series of systematic reviews exploring the relationship between intake, status and health outcomes for prioritised micronutrients (folate, Fe, vitamin $\mathrm{B}_{12}$, $\mathrm{Zn}$ and iodine). These systematic reviews will focus on vulnerable populations including infants and children, pregnant and lactating women, the elderly and immigrant and low-income groups, and will provide a comprehensive overview that can be used to derive micronutrient requirements and dietary recommendations.

1. Fairweather-Tait SJ \& Harvey LJ (editors) (2008) Micronutrient status methods: Proceedings of the EURRECA workshop and working party on new approaches for measuring micronutrient status. Br J Nutr 99, Suppl. 3.

2. Fairweather-Tait SJ, Harvey LJ, Casgrain A, Hooper L, guest editors (2009). Biomarkers of Micronutrient Status: EURRECA Workshop. Am J Clin Nutr 89 (6S) 